\title{
DNTT Positive
}

National Cancer Institute

\section{Source}

National Cancer Institute. DNTT Positive. NCI Thesaurus. Code C162085.

An indication that DNTT expression has been detected in a sample. 